\title{
Erzincan İli Zemin Büyütme Etkilerine Dayalı Mikrobölgeleme Çalışması
}

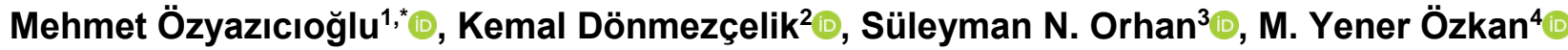

${ }^{1}$ Atatürk Üniversitesi, Deprem Araştırma Merkezi, 25240, Erzurum.

${ }^{2}$ Tarım ve Kırsal Kalkınmayı Destekleme Kurumu, 24100, Erzincan.

${ }^{3}$ Erzurum Teknik Üniversitesi, Mühendislik Fakültesi, Inşaat Mühendisliği Bölümü, 25100, Erzurum.

${ }^{4}$ Orta Doğu Teknik Üniversitesi Mühendislik Fakültesi, İnşaat Mühendisliği Bölümü, 06531, Ankara.

\section{Özet}

Erzincan İli 1. derece deprem bölgesi içinde yeralmaktadır. Zemin yüzeyinden ana kayaya kadar alüvyon kalınlı̆̆l $1 \mathrm{~km}$ yi bulan yerleşim alanında zemin büyütmesinin ayrıntılı olarak incelenmesinin gerekliliği açıktır. Bu çalışmada, Erzincan İl merkezi için bir boyutlu kayma dalgası teorisine dayanan, eşdeğer-doğrusal zemin büyütme analizleri yapılmıştır. Çalışmada, zemin profillerini belirlemek amacıyla, 1960-1980 yılları arasında Devlet Su Ișleri Genel Müdürlügünce (DSİ) açılmış ve derinlikleri 275 m'yi bulan sondaj kuyularına ait veriler kullanılmıştır. Eşdeğer-doğrusal büyütme analizleri EduShake/ProShake programı kullanılarak gerçekleştirilmiştir. Kuyu noktalarında oluşturulan profillerde, 8 farklı anakaya hareketi kullanılarak, zemin yüzeyinde oluşan ortalama hareketin ivme-zaman geçmişi ve ortalama PSA (görünür spektral ivme) grafikleri oluşturularak Türk Deprem Yönetmeliğinde (2007) verilen tasarım spektrumu ve ana kaya mostrası PSA ile karşılaştırılmıştır. Belirli periyotlar için, spektral ivme cinsinden büyütme oranları (ana kaya mostrası hareketine göre) hesaplanmıştır. Sondaj noktalarının temsil ettiği alanlarda, büyütmeye maruz kalması beklenen yapı periyotları haritada gösterilmektedir.

Anahtar Sözcükler

Zemin Büyütmesi, Depremler, Mikrobölgeleme, Erzincan, Kayma Dalgası, Eşdeğer-Doğrusal Analiz

\section{Microzonation Study Based on Ground Amplification for Erzincan City}

\begin{abstract}
Nearly all regions in Erzincan lie on a first degree earthquake zone. In the plains of the city, the thickness of the alluvial layer over the bedrock is about $1 \mathrm{~km}$. In this regard, it is clear that a detailed ground amplification analysis is required for the city settlement area. In this research, soil amplification analyses based on equivalent linear one dimensional shear wave theory have been made for the province of Erzincan. For this purpose, borehole (max depth $275 \mathrm{~m}$ ) data pertaining to DSI (State Water Works) drilled between 1960 and 1980 for ground water exploration are used. The equivalent linear ground motion analyses have been accomplished by EduShake/ProShake, a one dimensional shear wave analysis program. Eight different scaled real ground motion acceleration time histories are used to obtain surface motion PSA (Pseudo Spectral Acceleration). The average of PSA at each boring location is plotted together with bed rock outcrop PSA and 2007-Turkish Earthquake Code Design Spectrum. The amplification ratios for each period are computed by dividing surface PSA to bedrock outcrop PSA. The map of the city is divided into microzones, representing each boring log to display periods where computed amplifications are observed.
\end{abstract}

$\underline{\text { Keywords }}$

Ground Amplification, Earthquakes, Microzonation, Erzincan, Shear Wave, Equivalent Linear Analysis

\section{Giriş}

Erzincan, Doğu Anadolu Bölgesinin Kuzey-Batı bölümünde Yukarı Fırat Havzasında yer alan 1185 m rakımlı bir kentimiz olup, kuzey ve güneyinde yer alan dağ silsileleri arasında, doğu-batı uzanımlı toplam alanı $500 \mathrm{~km}^{2}$ 'yi bulan bir ova üzerinde yerleşmiştir. Erzincan, Kuzey Anadolu Fay (KAF) hattına çok yakın, tarih boyunca şiddetli depremlere maruz kalmış aktif tektonik bir alanda kurulmuş bir yerleşim birimidir. Çalışmamızda, Erzincan il merkezinin zemin büyütme analizleri yapılarak, büyütmenin baskın olduğu periyotlara göre mikro (alt) bölgelere ayrılmış ve bir mikro bölgeleme haritası oluşturulmuştur. Çalışmamız, Devlet Su İşleri Genel Müdürlüğüne ait derin su sondajlarına (DSİ 1981) dayalı analizleri içerdiği için, önceki çalışmalardan (Lav ve Ansal 1993; Erken vd. 1993; Şengezer 1993; Lav 1994) farklıdır. Hazırladığımız mikro bölge haritasının, Erzincan İli imar çalışmalarına 1şık tutacağı kanaatindeyiz.

\footnotetext{
* Sorumlu Yazar: Tel: +90 (442) 2312167 Faks: +90 (442) 3161717

E-posta: mehmetoz@atauni.edu.tr (Ozyazicioglu M) donmezcelik@hotmail.com (Dönmezçelik K), s.orhan@erzurum.edu.tr (Orhan S.N) myozkan@metu.edu.tr (Özkan M.Y)
} 
Çalışmamızda zemin büyütmesi hesapları, düşey ilerleyen kayma dalgası denkleminin frekans ortamında, eşdeğer lineer yaklaşımla çözümüne dayalıdır. Temel kayası mostrasında (rock outcrop) tanımlı deprem hareketi bu yönteme dayalı hesap yapan bir yazılım ile zemin yüzeyine taşınmaktadır. Zeminin varlığı, temel kayası hareketini değiştirmektedir; farklı frekanslarda yer hareketinin genliği, kaya mostrasına göre büyüyebilmektedir.

Çalışmamızda büyütme, hesaplanan zemin yüzeyi PSA değerlerinin, temel kaya mostrasındaki (rock outcrop) harekete ait PSA değerlerine bölünmesi yoluyla elde edilmektedir. Büyütme temel kaya üzerinde yer alan üst zemin katmanları içerisinde gerçekleşir, bu nedenle Erzincan gibi alüvyon birikintinin 900 metreyi bulduğu bir jeolojik profilde, zemin yapısının makul bir derinliğe kadar bilinmesi, büyütme analizleri açısından önemlidir. Erzincan Belediyesince yaptırılan İmar Planına esas zemin etütleri, bu açıdan yeterli derinlikte (sondaj derinlikleri 10-15 m) inceleme sağlamamaktadır (Rapor 2009). Bu açıdan DSI sondajları derinlik açısından çalışmaya daha uygundur ve çalışmamıza esas alınmıştır. Bu sondajlardan, hali hazırda Erzincan yerleşim alanına düşenler seçilerek zemin profilleri çıkarılmış ve her sondaj konumu için bir zemin büyütme analizi yapılmıştır. Her sondaj kuyusunun temsil ettiği alan, Theissen poligonları yoluyla belirlenmiş ve zeminde büyütme hesaplanan peryotlar esas alınarak bu alanlar renklendirilmek suretiyle mikro bölge haritası oluşturulmuştur. Büyütme değerleri literatürde Midorikawa yöntemi (Midorikawa 1987) olarak bilinen yaklaşımla da belirlenmiş ve sonuçlar, kullanım kolaylığı açısından ayrıca bir tablo halinde de özetlenmiştir.

\subsection{Inceleme Alanının Jeolojisi ve Depremselliği}

Alüvyon kalınlığı 1000 m derinliklere varan Erzincan ovasında, ana kayaya kadar farklı kalınlıklarda zemin tabakaları bulunmaktadır. Çakı1lı-kum, killi-kumlu-çakıl, siltli-killi-çakıl ve siltli-çakıllı-kum tabakaları bulunan ovada, çakıl ve kum yatakları da sıkça görülmektedir. İl merkezinin geneline bakıldığında üst seviyelerde çakıl-kum bantları içeren siltli kil gözlenirken alt seviyelerde (ortalama 9-10 m'den sonra) az çakıllı-çakıllı kumlu-az kumlu-siltli-kil, killi-siltli-çakıllıkum, kumlu-çakıl gözlenmiştir. Gözlenen alüvyon birim heterojen bir yapı göstermekte olup yapılan laboratuvar deney sonuçlarına göre \%69 CL (çakıllı kumlu siltli kil), \%14 SM (çakıllı-killi-siltli-kum), yine \%14 GM (killi-kumlu-siltliçakıl) ve \%3 oranında SC (çakılll-siltli-killi-kum) oluşturmaktadır (URL-2 2009).

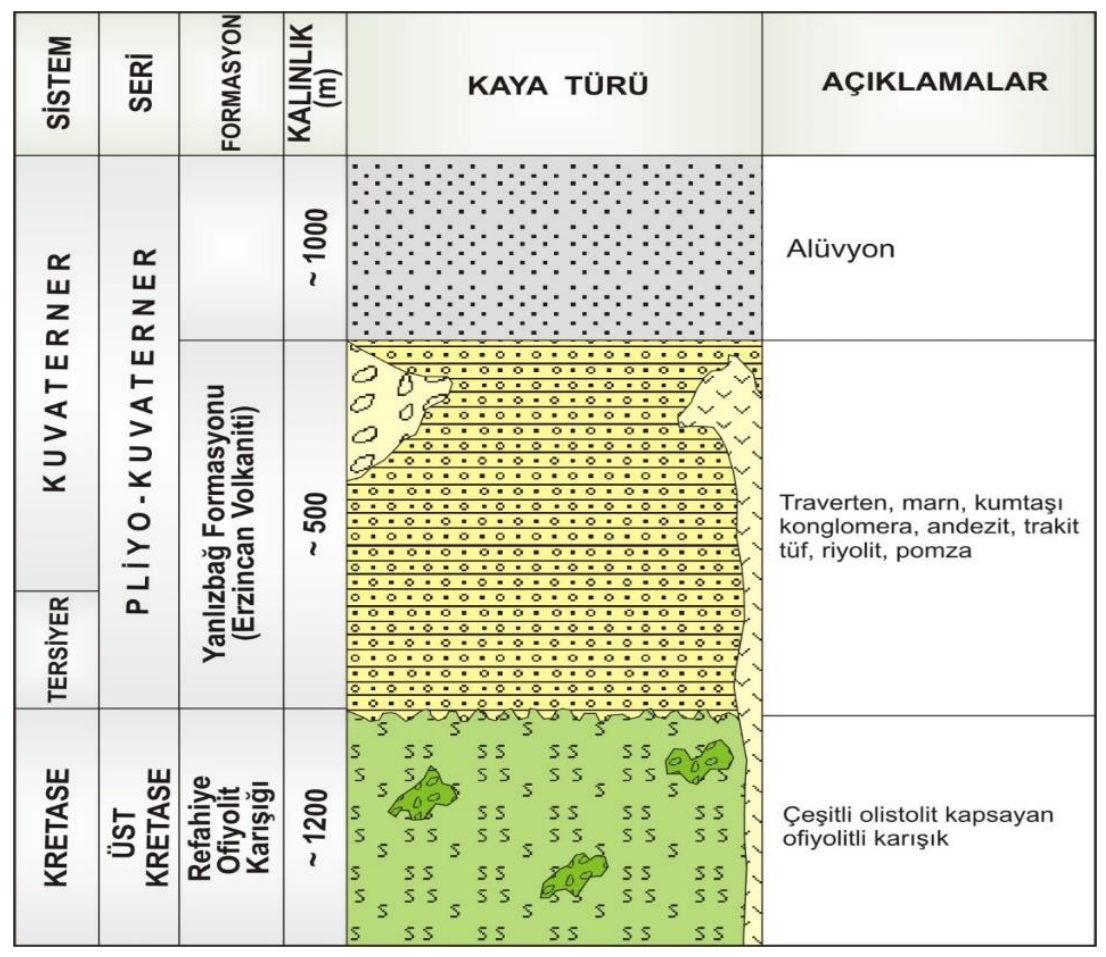

Şekil 1: Genelleştirilmiş stratigrafik kesit (Şengör ve Yılmaz 1981)

Erzincan Ovası paleotektonik açıdan Pontid, Torid ve Sakarya kıtasal bloklarının ve bunları ayıran ofiyolitik süturların, neotektonik açıdan ise sağ ve sol yanal atımlı fayların birbirine kavuştuğu bir düğüm noktasında yer alır. Bölge paleotektonik evrimini Liyas öncesinde Paleo-Tetis ve onun yayardı havzası olan Karakaya Okyanuslarının, Kretase sonunda ise Neo-Tetis Okyanusunun farklı kollarının kapanması ile kazanmıştır. Neo-Tetis'in kapanmasının ardından büyük ölçüde kara haline gelen bölge Eosen’de ve Alt Miyosen'de sı̆̆ denizlerle kaplanmıştır (Şekil 1). 
Ancak her iki denizel ortam da bölgenin kuzey-güney sıkışmalarla bindirmeli bir yapı kazanması ve yükselmesi yüzünden uzun ömürlü olmamışlardır. Alt Miyosen sonundan itibaren başlayan neo-tektonik dönemde bölgede kaçma tektoniği etkin olmuş, farklı atım ve uzanıma sahip yanal atımlı faylar gelişmiştir (Barka ve Gülen 1989).

Erzincan Ovası ve çevresinde hemen hemen yaşıt, ancak farklı doğrultularda üç grup yanal atımlı fay bulunmaktadır. Bunlardan ilki kuzeydeki Kuzeydoğu Anadolu Fayı, Karadeniz dağ sırasını güneyden sınırlayan sol yönlü doğrultu atımlı bir faydır. İkinci fay sistemi Erzincan Ovası'nın kuzey ve güneyinde geniş bir zonda izleri görülen sağ yönlü doğrultu atımlı Kuzey Anadolu Fay Sistemi'dir. Üçüncü fay ise Erzincan Ovası'ndan Ovacık ilçesine doğru kuzeydoğu-güneybatı yönünde uzanan sol yönlü doğrultu atımlı Ovacık Fayı'dır (Şekil 2).

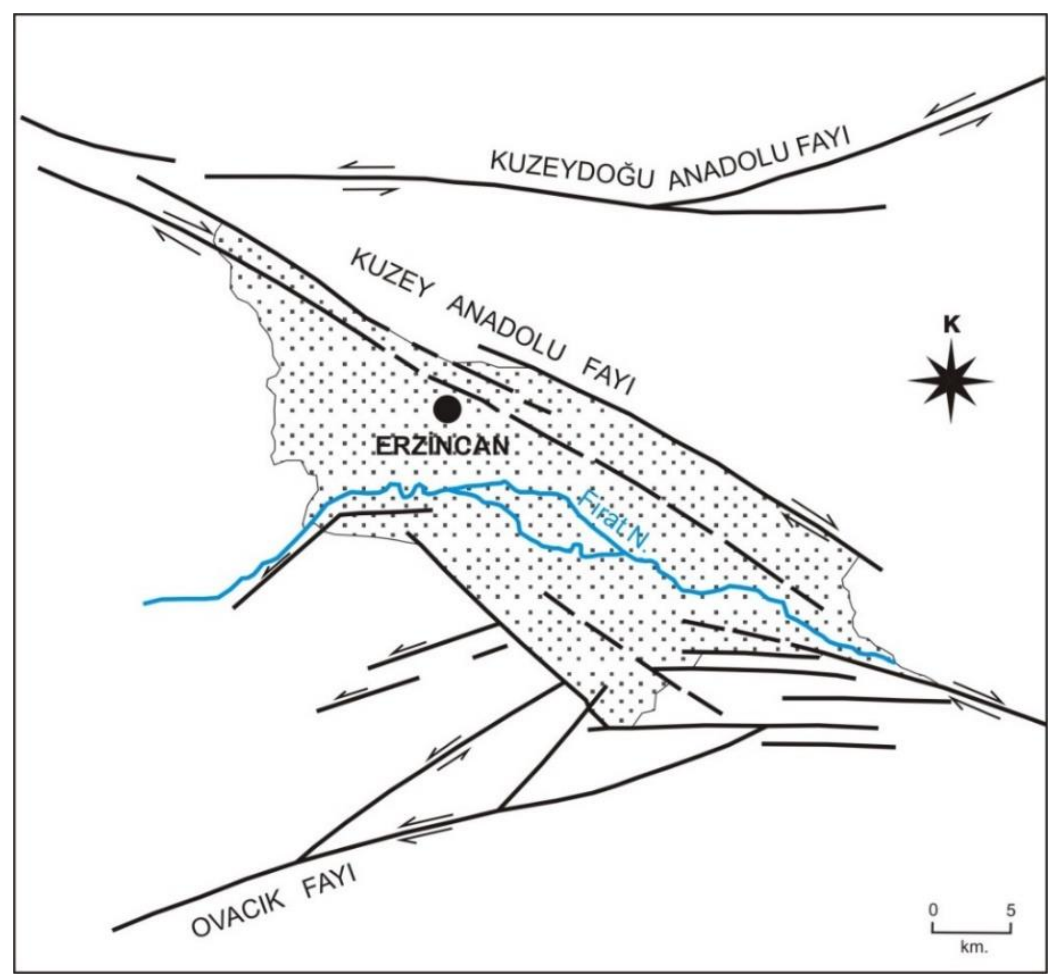

Şekil 2: Erzincan ovası çevresindeki ana fay sistemleri (Barka ve Gülen 1989)

Bu tektonik rejim altında kent, tarihte pek çok şiddetli deprem yaşamıştır. Kaynaklara göre, tarihsel dönemde 1045, 1268, 1458, 1482, 1584 yıllarında yaşanan depremlerde büyük hasar ve can kaybı meydana gelmiştir. Aletsel dönemde ise $1939(\mathrm{Ms}=7.8)$ ve $1992(\mathrm{Mw}=6.8)$ sarsıntıları maddi hasara ve can kaybına yol açmıştır.

\section{Materyal ve Yöntem}

Deprem esnasında ana kayadan yayılan dalgalar geçtikleri zemin tabakalarının mekanik özelliklerinden etkilenirler ve yeryüzüne ulaştıklarında daha şiddetli hissedilebilirler. Farklı zemin tabakaları deprem dalgalarını bir sonraki tabakaya aktarırken yatay ve düşey yöndeki deplasman genliklerini değiştirirler. Çok küçük değere sahip ana-kaya ivmeleri, yerel koşulların etkisi ile bazı bölgelerde birkaç kat büyüyerek çok ağır hasara neden olabilmektedir (Kramer 1996), bu olaya zemin büyütmesi adı verilmektedir.

Depremler sırasında oluşan ve her yöne hareket eden cisim dalgaları, tabaka sınırlarında gelme açısından daha küçük bir açıya kırılarak (dalga yayılma hızı yüzeye yaklaştıkça genel olarak küçüldüğü için) ilerlemekte ve zemin yüzeyine ulaştıklarında ise, yayılma doğrultuları hemen hemen yüzeye dik duruma gelmektedir. Bu nedenle incelenen bir bölgede yerel koşullara bağlı olarak deprem dalgalarının özelliklerinde meydana gelen değişimlerin belirlenmesinde en basit yaklaşım, düşey yönde ilerleyen kayma dalgası yayılımına dayanan bir boyutlu dinamik analizdir. Bu yöntemde ana kaya ve ana kaya üzerindeki bütün zemin tabakalarının yatay yönde sonsuza uzandığı kabul edilmekte ve her tabakaya ait transfer fonksiyonu belirlenerek yüzeydeki hareketin genliği dolayısıyla zemin büyütmesi hesaplanmaktadır (Kramer 1996; Özkan 2017).

Bu çalışmada topoğrafik etkiler göz ardı edilerek, bir boyutlu kayma dalgası modeline dayanan, eşdeğer doğrusal analiz yöntemi benimsenmiştir. Yöntemin teorisi pek çok kaynakta (Kramer 1996; Özkan 2017) anlatıldığından burada tekrarlanmayacaktır. Bu teoriyi kullanan çeşitli analiz programları bulunmaktadır.

Bu çalışmada analizler, EduShake/ProShake yazılımı (Schnabel vd. 1972) kullanılarak yapılmıştır. Anakaya mostrasındaki yer hareketi olarak 8 farklı gerçek deprem kaydı (El Centro, Gilroy 1, Gilroy 2, Petrolia, Taft, Topanga, 
Santa Cruz, Yerba Buena), en büyük ivme $0.4^{*}$ g'ye ölçeklendirilerek kullanılmış ve zemin büyütmesi için, her kuyu lokasyonunda, yüzey hareketlerinin ortalaması alınmıştır.

Zemin profillerini oluşturmak için DSİ su sondaj loglarından Erzincan'da ki meskûn mahallere denk düşen 41 tanesi kullanılmıştır. EduShake/ProShake programı zemini normalize edilmiş kayma modülü azalım ve sönüm eğrileri kullanılarak modellemektedir (Seed ve Idriss 1970; Vucetic ve Dobry 1991). Gerekli dinamik zemin özellikleri, DSİ sondaj profillerine ait bilgilerden aşağıdaki ampirik bağıntılar (Hardin ve Drnevich 1972; Prakash 1981) yardımıyla hesaplanmıştır:

$$
\begin{aligned}
& G=\frac{6908 *(2,17-\mathrm{e})^{2}}{1+\mathrm{e}} * \sqrt{\sigma_{0}} \\
& G=\frac{3230 *(2,97-\mathrm{e})^{2}}{1+\mathrm{e}} *(O C R)^{K} * \sqrt{\sigma_{0}^{l}} \\
& \sigma_{0}^{l}=\frac{1}{3} *\left(\sigma_{v}^{l}+\sigma_{h}^{l}\right) \\
& \sigma_{h}^{l}=K_{0} * \sigma_{v}^{l} \\
& \left.\sigma_{v_{i}}^{l}=\gamma_{e f f_{i}} * \frac{h_{i}}{2}, \sigma_{v_{i+1}}^{l}=\gamma_{e f f_{i}} * h_{i}+\gamma_{e f f_{i+1}} * \frac{h_{i+1}}{2}\right) \\
& \gamma_{e f f}=\gamma_{d r y}\left(\text { kuru zeminlerde) }, \gamma_{e f f}=\gamma_{s a t}-\gamma_{w}\right. \text { (suya doygun zeminlerde) } \\
& \mathrm{e}=\frac{G_{s}}{\gamma_{d r y}}-1 \text { (kuru zeminlerde), } \mathrm{e}=\frac{G_{s}-\gamma_{s a t}}{\gamma_{s a t}-\gamma_{w}} \text { (doygun zeminlerde) }
\end{aligned}
$$

Yukarıdaki ifadelerde;

$\mathrm{G} \quad$ : kayma modülü $\left(\mathrm{kN} / \mathrm{m}^{2}\right)$

e : boşluk oranı

$\sigma_{h}^{l} \quad: \quad$ yatay efektif basinç $\left(\right.$ ton $\left./ m^{2}\right)$

$\sigma_{v}^{l} \quad:$ düşey efektif basınç $\left(\right.$ ton $\left./ \mathrm{m}^{2}\right)$

$G_{s} \quad:$ özgül ağırlık $\left(2,5<G_{s}<2,8\right.$ olduğundan hesaplamalarda ortalama bir değer olarak 2,65 kabul edilmiştir)

$\gamma_{\text {eff }}:$ efektif birim hacim ağırlık $\left(\right.$ ton $\left./ \mathrm{m}^{3}\right)$

$\gamma_{\text {sat }}:$ doygun birim hacim ağırlık $\left(\right.$ ton $\left./ \mathrm{m}^{3}\right)$

$\gamma_{d r y}:$ kuru birim hacim ağırlık $\left(\right.$ ton $\left./ \mathrm{m}^{3}\right)$

$\gamma_{w}:$ suyun birim hacim a

$h_{i} \quad: \quad$ i. Tabakaya ait kalınlık $(m)$

OCR : aşırı konsolidasyon oranı (Erzincan ovasında zemin tabakalarının aşınmadığ 1 ve dolayısıyla normal konsolide olduğu düşünülerek $\mathrm{OCR}=1$ kabul edilmiştir.)

\begin{tabular}{|c|c|c|c|c|}
\hline & & Sıkılık Durumu & Kuru & Suya Doygun \\
\hline \multirow{9}{*}{ 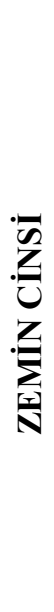 } & \multirow{2}{*}{ Silt } & Gevşek & 16 & 18 \\
\hline & & S1k1 & 17 & 19 \\
\hline & \multirow{2}{*}{ Kil } & Gevşek & 16 & 18 \\
\hline & & Sik1 & 17 & 19 \\
\hline & \multirow{2}{*}{ Kum } & Gevşek & 17 & 19 \\
\hline & & S1k1 & 18 & 20 \\
\hline & \multirow{2}{*}{ Çakıl } & Gevşek & 18 & 20 \\
\hline & & Sik1 & 19 & 21 \\
\hline & Konglomera & & 17 & 19 \\
\hline
\end{tabular}

$K_{0} \quad$ : sükûnetteki toprak basıncı katsayısı (Erzincan zemini yüzeye yakın derinliklerde bile suya doygun olduğundan, bu değer 0.5 kabul edilmiştir.)

Zemin birim hacim ağırlıkları, sondaj loglarındaki zemin tarifine uygun olarak Tablo 1 'de verilen tipik değerlerden alınmıştır. Bu yaklaşıma göre, DSİ-11094 no'lu sondaj profiline ait hesaplanmış zemin özellikleri Tablo 2'de verilmektedir. Diğer sondaj kuyuları için hesaplanan parametreler Dönmezçelik (2015)'te verilmiştir.

Tablo 1: Çalışmada karşılaşılan zemin cinslerine göre kullanılan tipik zemin birim hacim ağırıkları $\left(\mathrm{kN} / \mathrm{m}^{3}\right)$ 
Tablo 2: DSi-11094 no'lu sondaj profili için hesaplanan zemin özellikleri

\begin{tabular}{|c|c|c|c|c|c|c|c|c|c|}
\hline No & Katmanlar & $\mathbf{G m a x}$ & $\mathbf{H}$ & $\boldsymbol{\gamma}$ & $\mathbf{D} / \mathbf{K}$ & $\mathbf{e}$ & $\boldsymbol{\sigma}_{\mathbf{0}^{\prime}}$ & $\boldsymbol{\sigma}_{\mathbf{v}}{ }^{\prime}$ & $\gamma_{\text {eff }}$ \\
\hline 1 & Moloz & 44805.46 & 41 & 1.9 & $\mathrm{~K}$ & 0.39 & 25.97 & 38.95 & 1.9 \\
\hline 2 & Moloz & 64469.19 & 50 & 2.1 & $\mathrm{D}$ & 0.50 & 70.27 & 105.4 & 1.1 \\
\hline 3 & Çakıllı Kil & 43387.30 & 8 & 2 & $\mathrm{D}$ & 0.65 & 91.27 & 136.9 & 1 \\
\hline 4 & Kumlu Çakıllı Kil & 48547.44 & 61 & 2 & $\mathrm{D}$ & 0.65 & 114.27 & 171.4 & 1 \\
\hline 5 & Çak1llı Kil & 71511.19 & 340 & 2 & $\mathrm{D}$ & 0.65 & 247.93 & 371.9 & 1 \\
\hline 6 & Taban Kayası (sonsuz) & \multicolumn{3}{|c|}{ vs $=2000 \mathrm{~m} / \mathrm{s}$} & \multicolumn{3}{c|}{ Yass:41 } \\
\hline
\end{tabular}

Erzincan ovasında temel kaya derinliği değişkendir. Bu nedenle, analizde kullanılan zemin profillerinde sondajın sona erdiği tabaka, DSİ raporunda verilen jeolojik kesitlere göre temel kayaya kadar devam ettirilmiştir. Temel kayanın kayma dalgası hızı $2000 \mathrm{~m} / \mathrm{s}$ alınmıştır.

\section{Araştırma Bulguları}

Yukarıda tarif edilen yöntemle, temel kaya mostrası ve yüzey hareketleri için PSA (Pseudo Spectral Acceleration-Sözde Spektral İvme) grafikleri oluşturularak, bu grafiklerin oranından (zemin yüzeyi spektrumu / kaya mostrası spektrumu) büyütmeler elde edilmiştir. PSA grafikleri oluşturulurken her bir taban kayası hareketi için ayrı ayrı elde edilen spektrumların ortalamaları kullanılmıştır. Bu çalışmada, büyütme ana kaya mostrasına göre ivme spaktrumlarının oranından hesaplanmış olup, EduShake/ProShake programı tarafindan üretilen ve yüzey hareketi ile taban kayası hareketinin Fourier genlik spektrumlarının oranı şeklinde hesaplanan büyütme spektrumu da karşılaştırma için sunulmuştur. Grafiklerde ayrıca her sondaj profili için 2007 Türk Deprem Yönetmeliği (TDY 2007; URL-1 2007) tasarım spektrumu da karşılaştırma için verilmiştir.

Şekil 3'te DSİ-11094 no'lu sondaj noktasına ait hesaplanan zemin yüzeyi hareketi ile Gilroy 1 depremi, temel kaya mostrasına ait ivme zaman grafikleri karşılaştırmalı olarak gösterilmektedir. Şekil 3'ten görüleceği üzere, bu zemin profilinde Gilroy 1 deprem kaydı için hesaplanan en büyük zemin yüzeyi ivmesi $(0.25 \mathrm{~g})$ temel kaya mostrası en büyük ivmesinden $(0.4 \mathrm{~g})$ küçüktür. Bu durum büyütme olmadığı anlamına gelmez. Büyütme, zeminin profilinin geometrik ve malzeme parametrelerine bağlı olarak, farklı frekanslarda gerçekleşebilir. Büyütmenin görülebilmesi için hareketlerin spektrumlarının karşılaştırılması gereklidir. Bu karşılaştırma Şekil 4’te yapılmaktadır.

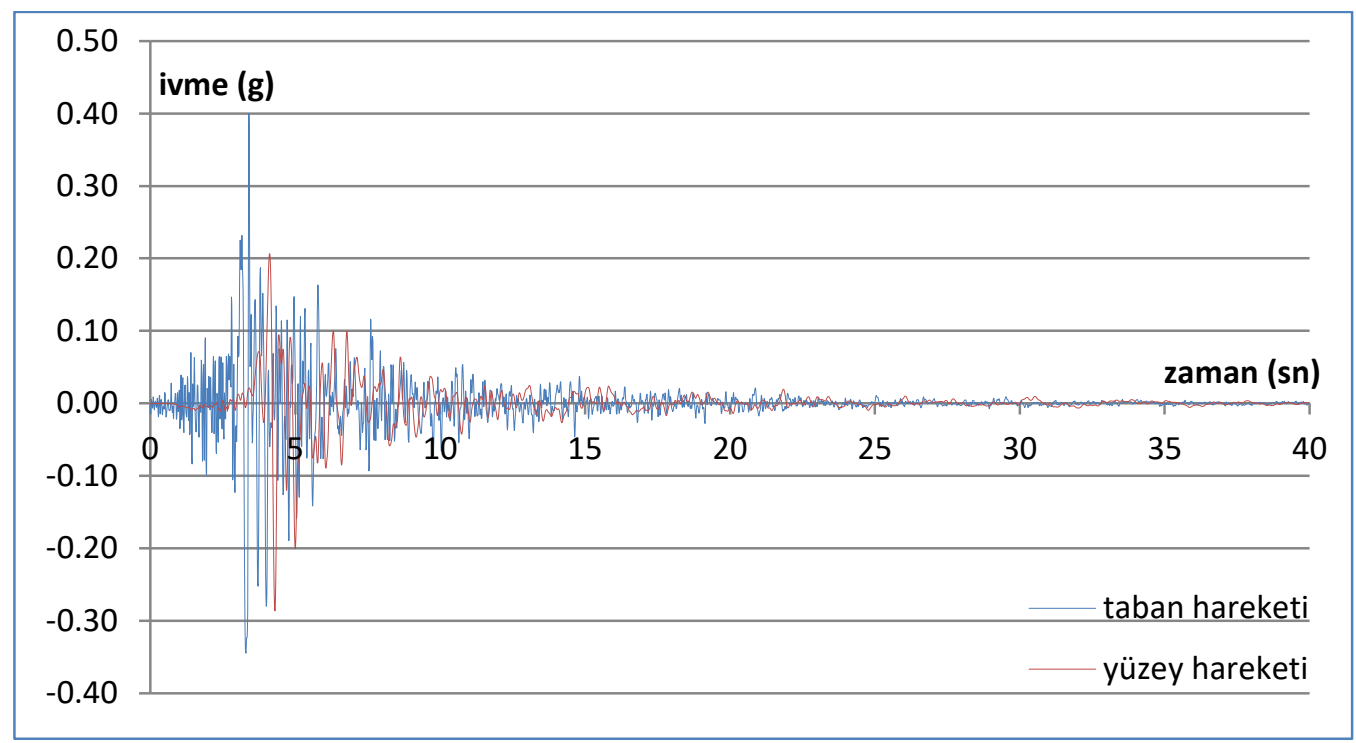

Şekil 3: DSi-11094 sondaj noktasında Gilroy 1 ana kaya mostrası deprem hareketi için hesaplanan zemin yüzeyi ivme zaman grafiği 


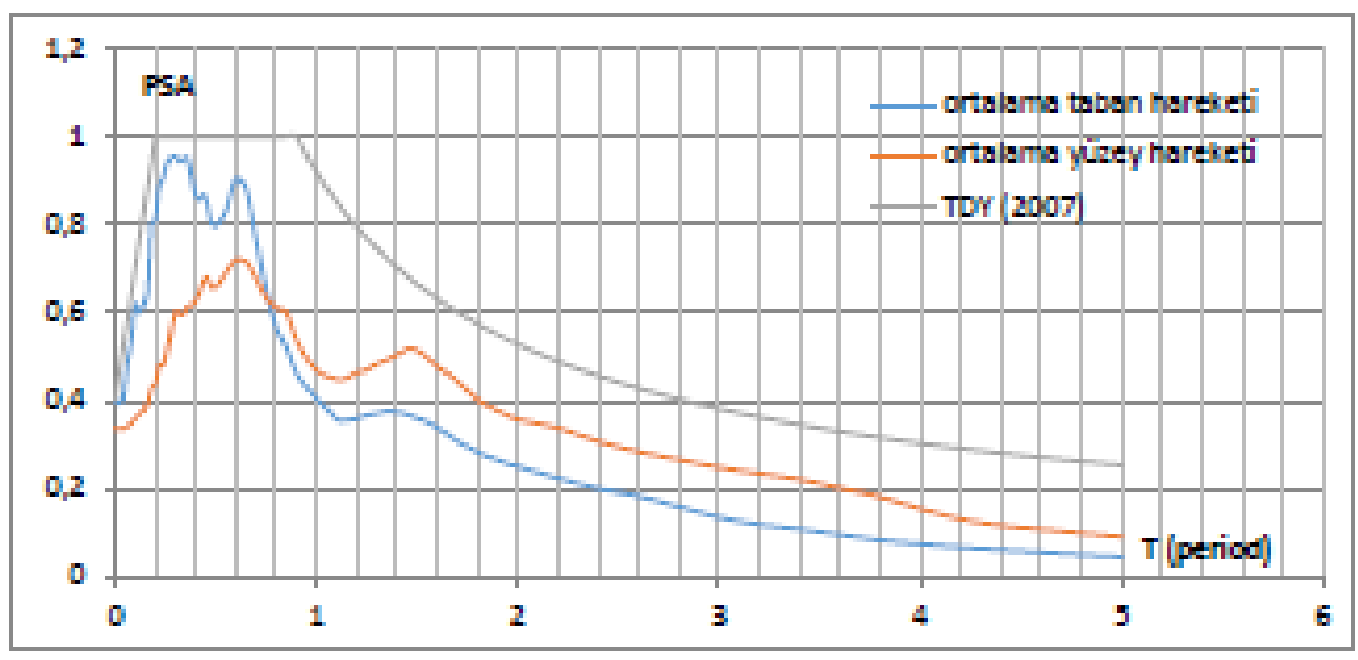

Şekil 4: DSi-11094 sondaj noktasında Gilroy 1 depremi için hesaplanan ana kaya mostrası ve zemin yüzeyi PSA grafikleri ve yerel zemin koşullarına göre belirlenmiş 2007 TDY tasarım spektrumu

Şekil 4'te 8 farklı deprem için zemin yüzeyi ve ana kaya mostrasındaki ortalama PSA (ivme spektrumu) grafikleri, DSİ11094 sondaj profiline uygun (Z4 tip zemin belirlenmiștir) TDY-2007 tasarım spektrumu ile birlikte gösterilmektedir. Şekil incelendiğinde, Zemin yüzeyindeki hareketin genliğinin 0.9 sn periyoduna kadar, ana kaya mostrasından daha düşük gerçekleştiği ancak bu periyottan sonra yüzey ivmesi genliğinin büyüdüğü gözlenmektedir. Şu halde periyodu 0.9 sn değerinden büyük yapılar, ana kaya üzerindekilere göre daha büyük ivmelere maruz kalacaklardır. Şekil 4 'te 2007-TDY tasarım spektrumunun hem kaya mostrası hem de zemin yüzeyi PSA grafiklerinden yukarıda kaldığı görülmektedir. Bu durum incelenen 41 zemin profilinin hemen tamamında aynen tezahür etmiștir. Şu halde, Erzincan'da 2007 Deprem Yönetmeliğine göre tasarlanan yapıların zemin büyütme etkilerine karşı güvenli tarafta kaldıkları düşünülebilir.

Şekil 5 'te Edushake/Proshake programının Gilroy 1 depremi için ürettiği büyütme spektrumu görülmektedir. $\mathrm{Bu}$ grafik, program tarafindan hesaplanan yüzey-deplasman genlik spektrumu, taban kayası genlik spektrumuna bölünerek elde edilmektedir. Bu nedenle, büyütme periyotları ve büyütme oranları farklı çıkabilmektedir. Şekil 5 incelendiğinde büyütmenin en fazla $3.5 \mathrm{sn}$ periyodunda gerçekleştiği, ikinci bir büyütmenin ise $1.5 \mathrm{sn}$ periyodu civarında gerçekleşeceği görülmektedir. Bu sonuçlar Şekil 4'te elde edilenlerle uyumludur.

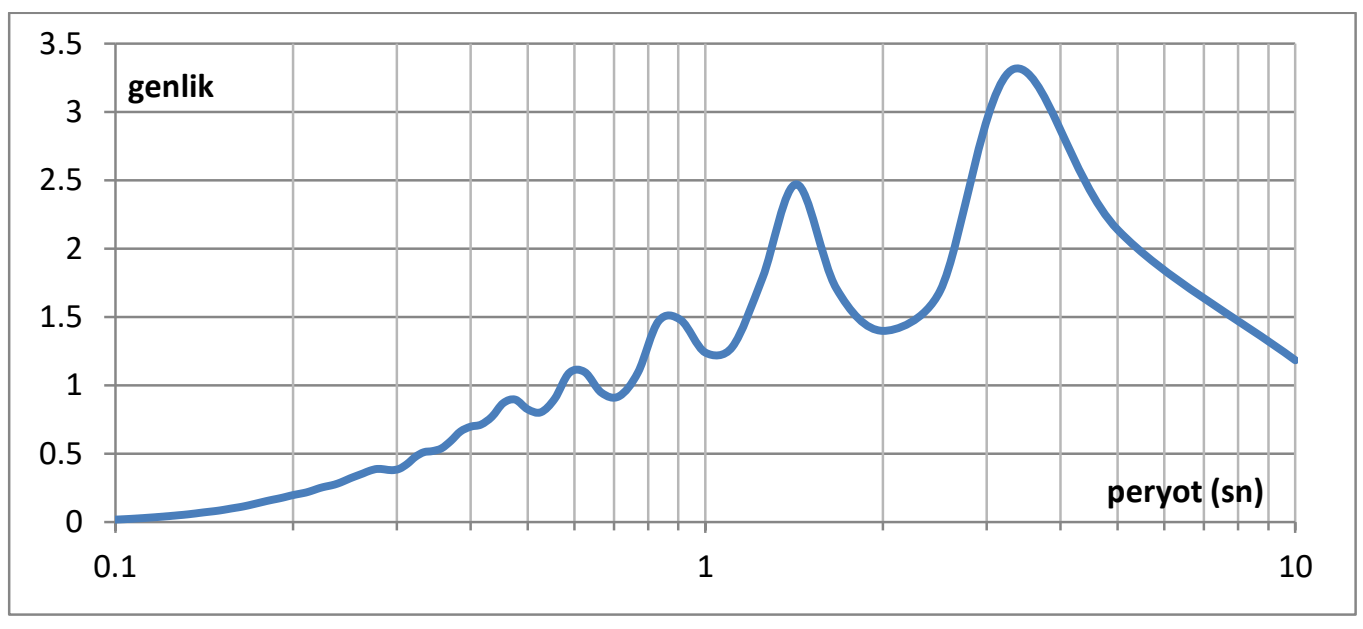

Şekil 5: DSI-11094 sondaj noktasında program tarafından hesaplanan büyütme spektrumu

Elde edilen sonuçlar toplu olarak Tablo 3'te özetlenmektedir. Tablodaki kat aralıkları, hâkim titreşim periyodu ile bina kat adedini yaklaşık olarak ilişkilendiren $\mathrm{T}=\mathrm{N} / 10$ ( $\mathrm{N}$ kat adedi) formülü ile belirlenmiştir. Tüm profillere ait büyütme çalışması birleştirilerek sonuçlar haritaya aktarılmıştır. Her profil, haritada bir noktaya denk geldiği için bu noktanın Erzincan'da temsil ettiği alan Theissen poligonları tekniği (Usul 2001) ile belirlenmiştir. Bu şekilde Erzincan kenti için zemin büyütme etkilerine göre bir mikrobölgeleme haritası oluşturulmuştur (Şekil 6). 


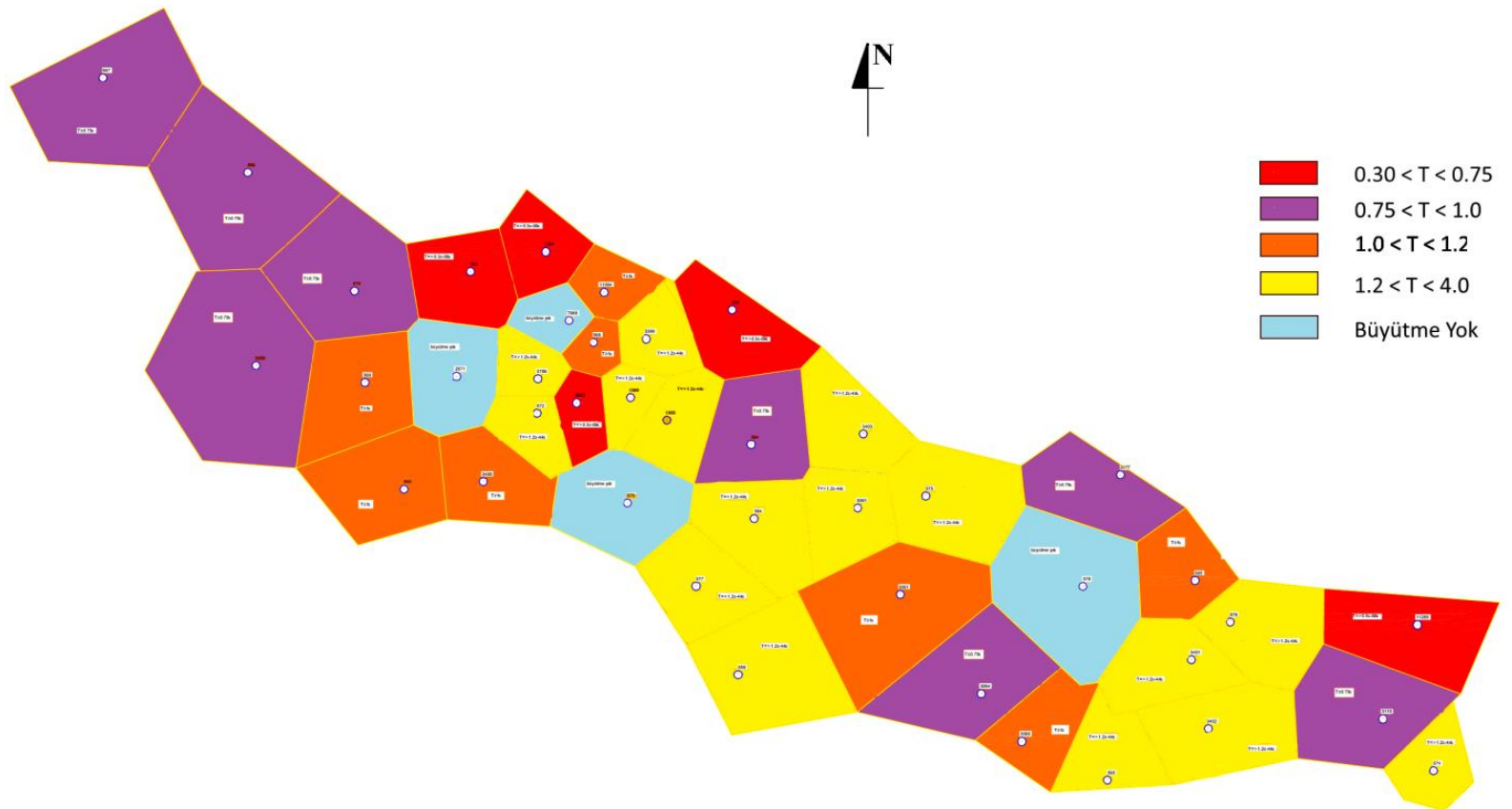

Şekil 6: Erzincan Ili için bir boyutlu zemin büyütme analizlerine dayalı mikrobölgeleme haritası (Ölçek 1:106)

Şekil 6 Erzincan İl merkezindeki farklı mikro-bölgelerde zemin yüzeyinde ana kaya mostrasına göre hangi periyotlarda büyütme hesaplandığını göstermektedir. Büyütme oranları da Tablo 3 'te verilmektedir.

Tablo 3: Tüm sondaj profilleri için elde edilen büyütme bilgilerinin özeti

\begin{tabular}{|c|c|c|c|c|c|}
\hline \multirow{2}{*}{ No } & \multirow{2}{*}{$\begin{array}{l}\text { Sondajın } \\
\text { Kodu (DSI) }\end{array}$} & \multirow{2}{*}{$\begin{array}{l}\text { Büyütmeden Etkilenen } \\
\text { Yapı Periyotları }\end{array}$} & \multirow{2}{*}{$\begin{array}{l}\text { Büyütmeden Etkilenmeyen } \\
\text { Kat Aralıkları }\end{array}$} & \multicolumn{2}{|c|}{ Büyütme Oranları } \\
\hline & & & & $\mathrm{T}=0.3 \mathrm{~s}$ & $T=1 s$ \\
\hline 1 & 11094 & $\mathrm{~T} \geq 0.8 \mathrm{~s}$ & $0-8$ & 0.63 & 1.15 \\
\hline 2 & 7669 & $\mathrm{~T} \geq 1.6 \mathrm{~s}$ & $0-16$ & 0.25 & 0.71 \\
\hline 3 & 568 & $\mathrm{~T} \geq 0.6 \mathrm{~s}$ & $0-6$ & 0.58 & 1.36 \\
\hline 4 & 3399 & $\mathrm{~T} \geq 1.6 \mathrm{~s}$ & $0-16$ & 0.31 & 0.66 \\
\hline 5 & 1364 & $\mathrm{~T} \geq 0.4 \mathrm{~s}$ & $0-4$ & 0.8 & 1.24 \\
\hline 6 & 563 & $\mathrm{~T} \geq 0.6 \mathrm{~s}$ & $0-6$ & 0.71 & 1.58 \\
\hline 7 & 562 & $\mathrm{~T} \geq 0.4 \mathrm{~s}$ & $0-4$ & 0.89 & 1.10 \\
\hline 8 & 3059 & $\mathrm{~T} \geq 0.8 \mathrm{~s}$ & $0-8$ & 0.56 & 1.18 \\
\hline 9 & 559 & $\mathrm{~T} \geq 1.5 \mathrm{~s}$ & $0-15$ & 0.42 & 0.76 \\
\hline 10 & 1365 & $\mathrm{~T} \geq 1.8 \mathrm{~s}$ & $0-18$ & 0.41 & 0.75 \\
\hline 11 & 584 & $\mathrm{~T} \geq 1.8 \mathrm{~s}$ & $0-18$ & 0.28 & 0.72 \\
\hline 12 & 564 & $\mathrm{~T} \geq 0.5 \mathrm{~s}$ & $0-5$ & 0.85 & 1.26 \\
\hline 13 & 3786 & $\mathrm{~T} \geq 1.6 \mathrm{~s}$ & $0-16$ & 0.31 & 0.71 \\
\hline 14 & 572 & $\mathrm{~T} \geq 1.2 \mathrm{~s}$ & $0-12$ & 0.35 & 0.84 \\
\hline 15 & 570 & $\mathrm{~T} \geq 0.7 \mathrm{~s}$ & $0-7$ & 0.67 & 1.33 \\
\hline 16 & 1366 & $\mathrm{~T} \geq 1.2 \mathrm{~s}$ & $0-12$ & 0.29 & 0.81 \\
\hline 17 & 2607 & $\mathrm{~T} \geq 0.6 \mathrm{~s}$ & $0-6$ & 0.6 & 1.35 \\
\hline 18 & 2622 & $\mathrm{~T} \geq 0.3 \mathrm{~s}$ & $0-3$ & 0.91 & 1.69 \\
\hline 19 & 2671 & Büyütme yok & Kat Sinırı yok & 0.39 & 0.79 \\
\hline 20 & 560 & $\mathrm{~T} \geq 0.9 \mathrm{~s}$ & $0-9$ & 0.49 & 1.04 \\
\hline 21 & 3400 & $\mathrm{~T} \geq 1 \mathrm{~s}$ & $0-10$ & 0.37 & 0.95 \\
\hline 22 & 3061 & $\mathrm{~T} \geq 0.9 \mathrm{~s}$ & $0-9$ & 0.49 & 1.06 \\
\hline 23 & 3063 & $3.2 \mathrm{~s} \geq \mathrm{T} \geq 1.4 \mathrm{~s}$ & $0-14$ & 0.36 & 0.75 \\
\hline 24 & 3064 & $\mathrm{~T} \geq 0.6 \mathrm{~s}$ & $0-6$ & 0.57 & 1.28 \\
\hline 25 & 3065 & $\mathrm{~T} \geq 1 \mathrm{~s}$ & $0-10$ & 0.45 & 0.94 \\
\hline
\end{tabular}


Tablo 3'ün devamı

\begin{tabular}{|c|c|c|c|c|c|}
\hline \multirow{2}{*}{ No } & Sondajın & Büyütmeden Etkilenen & Büyütmeden Etkilenmeyen & \multicolumn{2}{|c|}{ Büyütme Oranları } \\
\cline { 4 - 6 } & Kodu (DSi) & Yapı Periyotları & Kat Aralıkları & T = 0.3 s & T = 1 s \\
\hline 26 & 565 & $\mathrm{~T} \geq 1 \mathrm{~s}$ & $0-10$ & 0.42 & 0.91 \\
\hline 27 & 566 & $\mathrm{~T} \geq 0.6 \mathrm{~s}$ & $0-6$ & 0.69 & 1.34 \\
\hline 28 & 567 & $\mathrm{~T} \geq 0.8 \mathrm{~s}$ & $0-8$ & 0.57 & 1.25 \\
\hline 29 & 573 & Büyütme yok & Kat Sınırı yok & 0.36 & 0.72 \\
\hline 30 & 574 & $\mathrm{~T} \geq 1 \mathrm{~s}$ & $0-10$ & 0.42 & 0.94 \\
\hline 31 & 575 & Büyütme yok & Kat Sınırı yok & 0.38 & 0.68 \\
\hline 32 & 577 & $\mathrm{~T} \geq 1.2 \mathrm{~s}$ & $0-12$ & 0.52 & 0.91 \\
\hline 33 & 578 & Büyütme yok & Kat Sınırı yok & 0.32 & 0.74 \\
\hline 34 & 579 & $\mathrm{~T} \geq 1 \mathrm{~s}$ & $0-10$ & 0.46 & 0.89 \\
\hline 35 & 585 & $\mathrm{~T} \geq 1 \mathrm{~s}$ & $0-10$ & 0.48 & 0.95 \\
\hline 36 & 3110 & $\mathrm{~T} \geq 0.65 \mathrm{~s}$ & $0-6$ & 0.84 & 1.41 \\
\hline 37 & 3401 & $\mathrm{~T} \geq 1.2 \mathrm{~s}$ & $0-12$ & 0.34 & 0.86 \\
\hline 38 & 3402 & $\mathrm{~T} \geq 0.7 \mathrm{~s}$ & $0-7$ & 0.47 & 0.95 \\
\hline 39 & 3403 & $\mathrm{~T} \geq 1 \mathrm{~s}$ & $0-10$ & 0.42 & 0.93 \\
\hline 40 & 11285 & $0.6 \mathrm{~s} \geq \mathrm{T} \geq 0.25 \mathrm{~s}$ & $0-2$ & 1.03 & 1.13 \\
\hline 41 & 569 & $\mathrm{~T} \geq 0.9 \mathrm{~s}$ & $0-9$ & 0.4 & 1.03 \\
\hline
\end{tabular}

Pratik uygulamalarda büyütme oranları Midorikawa yöntemi ile de hesaplanmaktadır (Midorikawa 1987). Çalışmamızda karşılaştırma için Midorikawa yöntemi ile de büyütme değerleri hesaplanmıştır. Bu yöntemde büyütme oranı

$\mathrm{A}=68 \mathrm{~V}_{\mathrm{S} 30^{-0.6}}$

ifadesi ile hesaplanmaktadır. Burada $\mathrm{V}_{\mathrm{S} 30}$ ilk 30 metrelik zemin katmanı için ortalama kayma dalgası hızıdır. Çalışmamızda her sondaj profilinde ilk 30 metre için hesaplanan zemin parametrelerinin ortalaması alınarak $\mathrm{V}_{\mathrm{S} 30}=\sqrt{\mathrm{G} / \rho}$ ifadesi ile belirlenmiştir. Midorikawa yöntemiyle hesaplanan büyütme değerleri Tablo 4'te verilmektedir.

Tablo 4: Tüm sondaj profilleri için Midorikawa yöntemiyle hesaplanan büyütme oranları

\begin{tabular}{|c|c|c|c|c|c|c|c|}
\hline No & Sondaj No & $\mathbf{V}_{\mathbf{s 3 0}}$ & Midorikawa'ya göre büyütme & No & Sondaj No & $\mathbf{V}_{\mathbf{s} 30}$ & $\begin{array}{c}\text { Midorikawa'ya göre } \\
\text { büyütme }\end{array}$ \\
\hline 1 & 11094 & 528 & 1.58 & 22 & 3061 & 312 & 2.17 \\
\hline 2 & 7669 & 373 & 1.95 & 23 & 3063 & 416 & 1.82 \\
\hline 3 & 568 & 439 & 1.77 & 24 & 3064 & 335 & 2.08 \\
\hline 4 & 3399 & 424 & 1.80 & 25 & 3065 & 467 & 1.70 \\
\hline 5 & 1364 & 516 & 1.60 & 26 & 565 & 424 & 1.80 \\
\hline 6 & 563 & 509 & 1.62 & 27 & 566 & 514 & 1.61 \\
\hline 7 & 562 & 513 & 1.61 & 28 & 567 & 460 & 1.72 \\
\hline 8 & 3059 & 462 & 1.71 & 29 & 573 & 457 & 1.72 \\
\hline 9 & 559 & 422 & 1.81 & 30 & 574 & 394 & 1.88 \\
\hline 10 & 1365 & 409 & 1.84 & 31 & 575 & 412 & 1.83 \\
\hline 11 & 584 & 430 & 1.79 & 32 & 577 & 490 & 1.65 \\
\hline 12 & 564 & 350 & 2.02 & 33 & 578 & 324 & 2.12 \\
\hline 13 & 3786 & 298 & 2.23 & 34 & 579 & 405 & 1.85 \\
\hline 14 & 572 & 455 & 1.73 & 35 & 585 & 423 & 1.81 \\
\hline 15 & 570 & 442 & 1.76 & 36 & 3110 & 333 & 2.08 \\
\hline 16 & 1366 & 315 & 2.16 & 37 & 3401 & 435 & 1.78 \\
\hline 17 & 2607 & 404 & 1.86 & 38 & 3402 & 437 & 1.77 \\
\hline 18 & 2622 & 332 & 2.09 & 40 & 11285 & 339 & 2.12 \\
\hline 19 & 2671 & 335 & 2.08 & 41 & 569 & 400 & 1.87 \\
\hline 20 & 560 & 405 & 1.85 & & & & \\
\hline 21 & 3400 & 414 & 1.83 & & & & \\
\hline
\end{tabular}

Tablo 4’ten görüldüğü üzere Midorikawa yöntemi, büyütmeyi periyotla ilişkilendirmemektedir. Her periyot için tek bir büyütme değeri hesaplamaktadır. Bu yöntemle hesaplanan büyütme değerleri her zaman birden büyüktür $(\mathrm{A}>1)$. 


\section{Sonuçlar ve Öneriler}

Bu çalışmada Erzincan ili imara açık alanda, DSİ sondaj verileri esas alınarak, bir boyutlu eşdeğer lineer kayma dalgası teorisine dayalı zemin büyütme analizleri yapılarak, belirli periyotlara sahip yapıların hangi bölgelerde zemin büyütmesi tehlikesi altında olduğu araştırılmıştır. Analiz sonuçları Tablo 3'te özetlenmiş ve Şekil 6'da harita üzerinde görselleştirilmiştir.

Zemin büyütme analizi sonuçları incelendiğinde, Erzincan Ovasında, yapı periyoduna bağlı olarak, bazı mikro bölgelerde iki kata varan oranda büyütmeler olduğu gözlenmiştir. Gözlenen bu büyütmeler, yerel zemin koşullarının deprem yer hareketleri üzerindeki etkilerinin varlığını doğrulamaktadır.

Analizler sonucunda elde edilen mikro-bölgeleme haritası, yeni inşa edilecek yapıların tasarımında ve mevcut yapıların depreme dayanıklılığının değerlendirilmesinde yararlı olacaktır. Daha güvenli yapılaşma için oluşturulan güvenli kat aralıkları dikkate alınabilir. Olası bir depremde oluşabilecek hasarların en aza indirilmesi için yapı hakim periyotlarının zemin hâkim periyotları aralığında olmasından kaçınılmalıdır.

Oluşturulan büyütme haritasına göre, ovanın temel kayaya yakın (temel kayasının yüzeye yaklaştığı) kısımlarında küçük periyotlu yapıların, büyük periyotlu yapılara göre zemin büyütme etkilerine daha fazla maruz kaldıkları görülmektedir. Yüzey ve yüzey altı topoğrafyasının büyütmeye etkilerinin de anlaşılabilmesi için, iki ve üç boyutlu dalga yayılım modelleri ile zemin büyütme analizleri yapılmalıdır. Yüzey altı topoğrafyasındaki düzensizlikler ovanın bazı kısımlarında ilave büyütme etkilerine yol açabilir.

Taksim, Çarşı ve Mimar Sinan mahallelerinin bazı kısmları için büyütmenin olmadığı kat aralıkları, 0-3 olarak tespit edilmiştir. Bu mahallelerde 4 kat ve üzeri yapılar için 1.69 oranında büyütme hesaplanmıştır. Bu mahallelerde kısmen 4 katlı yapılaşma mevcuttur.

TDY-2007 tasarım spektrumu hemen her durumda hesaplanan zemin yüzeyi PSA değerlerinin üzerinde kalmıştır. Buna göre 2007 Deprem yönetmeliğine göre tasarlanan yapıların zemin büyütme etkilerine karşı da güvenli tarafta kaldıkları söylenebilir.

Mühendislik uygulamalarında ve zemin etüt raporlarında zemin büyütme oranlarını tahmin etmek için sıkça kullanılan Midorikawa yöntemi ile bu bölgede yüksek büyütme değerleri hesaplanmıştır. Bu nedenle bölgede yapılacak mühendislik amaçlı büyütme analizlerinde, Midorikawa yönteminin kullanılmamasının uygun olacağı kanaati oluşmuştur.

Bu çalışmada Erzincan için mikro-bölgeleme yalnızca zemin büyütme etkileri değerlendirilerek yapılmıştır. Diğer kriterler (sıvılaşma, v.b) esas alınarak farklı mikro-bölgeleme haritalarının de oluşturulması önerilmektedir.

\section{Teşekkür}

DSİ 8. Bölge Müdürlüğ̈’ne sondaj verilerine erişim sağladıkları için teşekkürlerimizi sunarız.

\section{Kaynaklar}

Barka A., Gülen L., (1989), Complex evolution of the Erzincan basin (Western Turkey), Journal of Structural Geology, 11(3), $275-283$. Dönmezçelik K., (2015), Erzincan ilinde imara açık alanda zemin büyütme analizleri hakkında bir araştırma, Yüksek Lisans Tezi, Atatürk Üniversitesi, Erzurum.

DSİ, (1981), Erzincan Ovası hidrojeolojik etüt raporu, DSİ Genel Müdürlüğ̈̈, Ankara, 150ss.

Erken A., Ansal A., Yıldırım H., Ülker R., (1993), Erzincan kentinde yerel zemin koşulları, 2. Ulusal Deprem Mühendisliği Konferansı Kitab1, TMMOB İnşaat Mühendisleri Odası İstanbul Şubesi/Deprem Mühendisliği Türkiye Milli Komitesi/İTÜ Yap1 ve Deprem Uygulama Araştırma Merkezi ortak yayın1, 355-362.

Hardin B.O., Drnevich V.P., (1972), Shear modulus and damping in soils, Journal of Soil Mechanics and Foundations Division, ASCE. 98(6), 667-692.

Kramer S.L., (1996), Geotechnical earthquake engineering, Prentice-Hall, New Jersey, USA, 708ss.

Lav A., Ansal A., (1993), Erzincan depreminde zemin büyütmesi, 2. Ulusal Deprem Mühendisliği Konferansı Kitab1, TMMOB İnşaat Mühendisleri Odası İstanbul Şubesi/Deprem Mühendisliği Türkiye Milli Komitesi/İTÜ Yapı ve Deprem Uygulama Araştırma Merkezi Ortak Yayın1, 363-372.

Lav A., (1994), İstanbul ve Erzincan şehirlerinde zemin büyütme etkilerine göre mikrobölgeleme, Doktora Tezi, İ.T.Ü. Fen Bilimleri Enstitüsü, İstanbul.

Midorikawa S., (1987), Prediction of isoseismal map in Kanto plain due to hypothetical earthquake, Journal of Structural Engineering, $33 \mathrm{~B}, 43-48$.

Özkan M.Y., (2017), Zemin dinamiğine giriş, Nobel Yayın Dağıtım, Ankara, Türkiye, 316ss.

Prakash S., (1981), Soil dynamics, McGrawHill, New York, USA, 419ss.

Rapor, (2009), Erzincan (merkez) belediyesinin imar planına esas jeolojik/jeoteknik etüt raporu, Are Jeoteknik Müh. Müş. İnş. Taah. ve Tic. Ltd. Şti., Ankara.

Schnabel P.B., Lysmer J., Seed H.B., (1972), Shake: a computer program for earthquake response analysis of horizontally layered sites, report no. ucb/eerc 72-12, Earthq. Eng. Research Center, University of California, Berkeley, California, https://www.resolutionmineeis.us/documents/schnabel-lysmer-seed-1972, [Erişim 4 Eylül 2018]. 
Seed H.B., Idriss I.M., (1970), Soil moduli and damping factors for dynamic response analyses, Technical Report EERRC-70-10, University of California, Berkeley, https://ntrl.ntis.gov/NTRL/dashboard/searchResults/titleDetail/PB197869.xhtml, [Erișim 4 Eylül 2018].

Șengezer B.S., (1993), 13 Mart 1992 Erzincan kentinde meydana gelen hasarn mahallelere göre irdelenmesi, 2. Ulusal Deprem Mühendisliği Konferansı Kitabı, TMMOB İnşaat Mühendisleri Odası İstanbul Şubesi/Deprem Mühendisliği Türkiye Milli Komitesi/İTÜ Yapı ve Deprem Uygulama Araștırma Merkezi Ortak Yayını, 404-413.

Sengör A.M.C., Y1lmaz, Y., (1981), Tethyan evolution of Turkey: A plate tectonic approach, Tectonophysics, Elsevier B.V.

URL-1, (2007), Deprem bölgelerinde yapılacak binalar hakkında yönetmelik, Bayındırlık ve İskân Bakanlı̆̆ı, Ankara, http://www.resmigazete.gov.tr/eskiler/2007/03/20070306-3.htm, [Erişim 4 Eylül 2018].

Usul N., (2001), Engineering hydrology, ODTU Geliştirme Vakfi Yayınc1lık, Ankara, Türkiye, 416 ss.

Vucetic M., Dobry R., (1991), Effect of soil plasticity on cyclic response. Journal of the Geotechnical Engineering Division, ASCE, 17(1), 89-107. 